\title{
The Effectiveness of Using Computer Integrated Anthropometry and Vertical Jump as Measuring Device
}

\author{
Arief Abdul Malik ${ }^{1, *}$, Lutfi Nur ${ }^{2}$ \\ ${ }^{1}$ Department of Physical Education, Faculty of Teacher Training and Education, Universitas Siliwangi, Tasikmalaya, Indonesia \\ ${ }^{2}$ Department of Elementary Teacher Education, Tasikmalaya Campus, Universitas Pendidikan Indonesia, Bandung, Indonesia
}

Received June 23, 2020; Revised September 7, 2020; Accepted September 17, 2020

\section{Cite This Paper in the following Citation Styles}

(a): [1] Arief Abdul Malik, Lutfi Nur, "The Effectiveness of Using Computer Integrated Anthropometry and Vertical Jump as Measuring Device," International Journal of Human Movement and Sports Sciences, Vol. 8, No. 5, pp. 161 - 165, 2020. DOI: 10.13189/saj.2020.080501.

(b): Arief Abdul Malik, Lutfi Nur (2020). The Effectiveness of Using Computer Integrated Anthropometry and Vertical Jump as Measuring Device. International Journal of Human Movement and Sports Sciences, 8(5), 161 - 165. DOI: 10.13189/saj.2020.080501.

Copyright $\mathrm{C} 2020$ by authors, all rights reserved. Authors agree that this article remains permanently open access under the terms of the Creative Commons Attribution License 4.0 International License

\begin{abstract}
This research aimed at determining the effectiveness of the use of computer-integrated anthropometrics and vertical jump as a measuring device. The participants were 42 students aged 18-21 years old. The research design used was counterbalanced-design. The instrument used was the Integrated Anthropometric Test (IAT) to measure body weight (BW), body height (BH), arm span (AS), limb length (LL), and vertical jump (VJ) in one set of device and compared with Standard Anthropometric Test (SAT) consist of anthropometric measurements including $\mathrm{BW}, \mathrm{BH}, \mathrm{AS}$ and LL that follow the standard procedure from the International Standards for Anthropometric Assessment (ISAK) and Sargent Jump test to measure vertical jumps. The results showed that the IAT and SAT measurements had a validity measurement value of BW measurements of 0.994 , BH of 0.969 , AS of 0.820 , LL of 0.745 , and VJ of 0.903 with $P<0.01$, and the total duration of the IAT measurement process was 36 minutes 18 seconds, SAT was 1 hour 7 minutes 27 seconds. It was concluded that the Integrated Anthropometric Test (IAT) had a very high validity value for the $\mathrm{BW}, \mathrm{BH}, \mathrm{AS}$, and VJ measurements and a high category for LL measurements so that it can be used as an anthropometric and vertical jump measurement device. As IAT had a shorter measurement duration than SAT, it can be said that IAT had a good level of effectiveness.
\end{abstract}

Keywords Anthropometry, Vertical Jump, Sports Technology

\section{Introduction}

Program for coaching and developing athletes in the developed countries has achieved their sporting achievements by obtaining adequate support from resources, not only support from the government and society but also the support from the experts through synergizing the scientific approaches [1]. Sophisticated measurements and evaluation devices and the discovery of the right instruments have encouraged us to work effectively in identifying and selecting talented athletes [2]. There are ten elements in identifying physical characteristics in identifying the athlete, namely agility, quickness, strength, power, endurance, coordination, flexibility, speed, vision, and anthropometrics [3,4]. From the tenth elements, two elements are often used in the identification of the initial athlete, namely the power test in the form of a vertical jump and an anthropometric test. Sidik [5] revealed that the dominant measurement was anthropometric measurement that had a more influential factor on the achievement were Body Height (BH), Body Weight (BW), Body Mass Index (BMI), Arm Span (AS), and Limb Length (LL).

Nowadays, anthropometric and vertical jump measuring devices have a variety of shapes and variations in their use. There are manual operating systems and digital operating systems. The previous research [6] revealed the limitations in manual anthropometric measurement, it required exhausting special training or certification and took a long duration in making many direct measurements during the 
examination. Another researcher [7] added that to have a digital vertical jump measurement device, it requires quite a lot of costs, as an illustration, Jump DF series TKK-5414 production by the Japanese Takei company is valued at IDR $107,000,000$ per one unit and the American AMTI-Accu Power Force Plate is valued IDR 635,300,000 per one set.

Technology in the field of sports has been widely used, especially in developed countries as an effort to improve sports performance and achievement. However, it cannot be neglected that Indonesia is still left behind in innovation and technological advancements due to its tendency as a technology consumer country [8,9]. Therefore, a collaboration between stakeholders, scientists, athletes, coaches, and practitioners, as well as academics, is needed to improve and develop sports science and technology to accelerate and optimize sports achievements and the creation of useful sports equipment.

The use of appropriate technology in measurement and training can help to improve the performance of athletes, both amateur and professional athletes [10]. The use of sensors and the right, as well as integrated with a good application program can help measurement activities. Therefore, the application of sports science in sports is a necessity in the development of sports technology to push achievement to a higher level.

Many previous studies have discussed the importance of anthropometric measurements for athletes in various sports fields such as soccer [11,12], volleyball [13], basketball [14], and their comparison to non-athletes [15]. But there is still limited research discussing the validity of anthropometric measurements, especially for sports measurements by utilizing a new technology.

Besides, the use of anthropometric measuring devices in Indonesia is usually carried out in the university admission test with the specifications sports department and also the entrance test of government institutions that require a medical checkup as one of the indicators of employee recruitment. This certainly requires a relatively long time to measure, record, and score the results or values of each of the anthropometric tests. It takes a lot of human resources to carry out the process, moreover, human error can occur due to misrepresentation of results or values. To overcome this, we need a tool that can help us to solve these problems and can be proved with transparent and fast results on one computer screen.

Therefore, researchers assume that it was very necessary to be able to test the validity of measurements and the effectiveness of anthropometric measuring instruments which included measurements of body height, body weight, arm span, limb length, and vertical jump measurements. All of these measurements could be measured through a device that was integrated with a computer and was named as Integrated Anthropometric Test (IAT).

\section{Materials and Methods}

This research was Quasi-Experimental Design research using the Counterbalanced Design method which was used to homogenize the experimental and control groups. Therefore, in this design, each group was given all treatments but in a different order [16]. This research design is commonly used in testing the validity of measuring instruments that have recently been developed by comparing to the existing measuring instruments $[17,18]$. In this case, the researcher tested the validity of the instrument that was made, namely the Integrated Anthropometric Test (IAT) compared to the existing standard tools, then the duration of the measurements was compared to see its effectiveness based on the duration needed by the two instruments in carrying out the measurement process.

Participants in this study were 42 students of the Sports Department at the Faculty of Sports and Health Education (FPOK), the Education University of Indonesia consisting of 28 man and 14 women aged 18-21 years $(19 \pm 0.71)$ who were in good health, do not experience minor or severe injury and agreed to give consent before participating in this study according to local ethics committee regulations.

The instruments used in this study were the Integrated Anthropometric Test (IAT) as a test instrument and the Standard Anthropometric Test (SAT) as a reference instrument. Integrated Anthropometric Test (IAT) was a tool developed by the researchers to measure height, arm length, limb length using an ultrasonic sensor, body weight measurement using a load cell sensor, and vertical jump measurement using a microcontroller-based infrared sensor in one tool. This IAT measurement was directly integrated with a computer so that the measurement results could be seen directly, and there was a data storage system that provides easiness for the researcher to do further data processing and data analysis. Meanwhile, the Standard Anthropometric Test (SAT) was a standard manual measurement that already exists, including the measurement of height and weight, measured using $\mathrm{Seca}^{\mathrm{TM}}$, the arm length and limb length using anthropometric tape with an accuracy of $0.1 \mathrm{~cm}$ which refers to the international measurement standard [19] and the vertical jump was measured by Sargent jump test using a vertical board to determine the height of the jump $[20,21]$.

The data analysis technique used in this research was a quantitative analysis technique to determine the validity of the test instrument using the Pearson product-moment correlation coefficient correlation test by utilizing SPSS 23 application. Furthermore, to determine the level of effectiveness of the tool, the total measurement time of the test instrument and reference instrument was compared. 


\section{Result}

Based on the results of the research that has been done, the results obtained by the measurement of IAT and SAT are presented in table 1 .

Table 1. The Result of IAT and SAT Measurement

\begin{tabular}{|c|c|c|}
\hline $\begin{array}{c}\text { Type of } \\
\text { Measurement }\end{array}$ & $\begin{array}{c}\text { Tester } 1 \\
\text { (IAT) }\end{array}$ & $\begin{array}{c}\text { Tester } 2 \\
\text { (SAT) }\end{array}$ \\
\hline Body Weight & \multirow{2}{*}{$61.98 \pm 7.13$} & \multirow{2}{*}{$60.88 \pm 6.85$} \\
\hline Mean \pm SD & & \\
\hline Body Height & \multirow{2}{*}{$168.87 \pm 8.16$} & \multirow{2}{*}{$167.88 \pm 7.90$} \\
\hline Mean \pm SD & & \\
\hline Arm Span & \multirow{2}{*}{$168.53 \pm 9.92$} & \multirow{2}{*}{$168.5 \pm 8.62$} \\
\hline Mean \pm SD & & \\
\hline Limb Length & \multirow{2}{*}{$97.10 \pm 6.91$} & \multirow{2}{*}{$97.4 \pm 5.50$} \\
\hline Mean \pm SD & & \\
\hline Vertical Jump & \multirow{2}{*}{$39 \pm 8.49$} & \multirow{2}{*}{$40.31 \pm 7.75$} \\
\hline Mean \pm SD & & \\
\hline
\end{tabular}

Table 1 shows the IAT measurement data with the average value of the measurement of body weight, body height, and arm span was higher than the SAT measurement. Meanwhile, the measurement of limb length and vertical jump using the SAT were higher than measurements using IAT.

Table 2. Validity Test Data of IAT and SAT Measurement

\begin{tabular}{|c|c|c|c|}
\hline No & Variable & Type of Measurement & \multirow{2}{*}{ Pearson's $r$} \\
\hline \multirow{2}{*}{1} & \multirow{2}{*}{ Body Weight } & IAT & \multirow{2}{*}{0.994} \\
\cline { 3 - 3 } 2 & \multirow{2}{*}{ Body Height } & SAT & \multirow{2}{*}{0.969} \\
\cline { 3 - 3 } & & IAT & \multirow{2}{*}{0.820} \\
\hline \multirow{2}{*}{3} & \multirow{2}{*}{ Arm Span } & SAT & \multirow{2}{*}{0.745} \\
\cline { 3 - 3 } & & IAT & \multirow{2}{*}{0.903} \\
\hline \multirow{2}{*}{5} & \multirow{2}{*}{ Limb Length } & SAT \\
\cline { 3 - 3 } & \multirow{2}{*}{ Vertical Jump } & IAT & \multicolumn{2}{|c|}{ SAT } \\
\cline { 3 - 3 } & & IAT & \multicolumn{2}{|c|}{ SAT } \\
\hline
\end{tabular}

Table 2 shows the results of the validity test of IAT and SAT measurements showing that the validity values of body weight, body height, arm span, and vertical jump obtained a very high validity category of $0.820-0.969$, while the measurement of limb length obtained the validity value of the high category.

To determine the effectiveness of the device, a comparison of the duration of the measurement between IAT and SAT is shown in Figure 1. The time duration includes (1) measurements of body weight and body height; (2) measurement of arm span and limb length; (3) measurement of vertical jump; (4) the exact time of measurement; and (5) total measurement time. In Figure 1 it can be seen that the measurement using the IAT required less time than using the SAT except for the measurement of arm span and limb length.

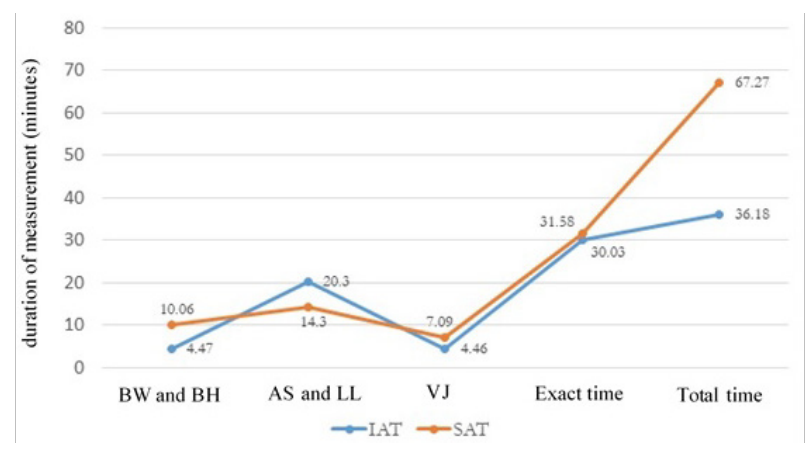

Figure 1. The Duration of IAT and SAT Measurement

Measurement of exact time was started when the test taker stood or got ready in front of the measuring instrument then the tester took the measurement, mentioned the measurement results, and ended when the tester recorded the measurement results. The exact time data for each measurement included (1) body weight and body height; (2) arm span and limb length; (3) vertical jump; then were calculated to be the exact time of measurement. Meanwhile, the total measurement time was the duration of time required by a test taker to perform all series of measurement types including $\mathrm{BW}, \mathrm{BH}, \mathrm{AS}, \mathrm{LL}$, and $\mathrm{VJ}$ in one measurement session including the displacement time of each measuring instrument.

\section{Discussion}

Research about testing the new measurement device, as well as measurement method in sports science, have been developed by some experts to improve performance in sports, such as the research [22] which developed an effective test to identify the talent of female hockey athlete by evaluating the anthropometric, physiological, and skill-related test. Other research was focused on anthropometric measurements, body composition, and strength variables as the prediction of jump results [23]. Besides, research [24] provided references to fitness and body size in basketball players based on the position and the playing characteristics were also carried out. Meanwhile, this research was initial research conducted by combining anthropometric measurements and vertical jumps in one set of measuring devices connected to a computer called the Integrated Anthropometric Test (IAT). The purpose of this study was to test the validity of the measurement device and the effectiveness of the Integrated Anthropometric Test (IAT) measurement device compared to the Standard Anthropometric Test (SAT).

The results of this study showed that all measurement sensors had reached their effectiveness. The ultrasonic sensors had been proved to be effective in measuring body 
height, arm span, and limb length. The use of this type of sensor is often used for distance measurements in various measurement applications [25,26]. The use of load cell sensors in measuring pressure or weight [27] was applied to measure body weight. An infrared sensor was used to measure the jump time which was applied to measure vertical jump $[28,29]$.

In the vertical jump measurement, the calculation of the jump height was obtained by entering the jump time value into the jump height formula proposed by Bosco, et al., [30]. as follows:

$$
\begin{gathered}
\text { jump height }(\mathrm{m})=\left(\mathrm{g} \times \mathrm{t}^{2}\right) / 8 \\
\mathrm{~g}=\text { acceleration due to gravity } 9.81 \mathrm{~m} / \mathrm{s}^{2} \\
\mathrm{t}=\text { jump duration (second) }
\end{gathered}
$$

In summary, the above equation was simplified by Young [25] as follows:

$$
\text { Jump height }(\mathrm{cm})=122.625 \times \mathrm{t}^{2}
$$

Bosco et al., [30] and Young [31] revealed that this method was valid to be used under the assumption that the position of the body in making a jump is in the same condition. It means that the test taker jumps and lands in the same place.

The validity test measurement showed the results of correlation measurements in the very high category for body weight (0.994), body height (0.969), arm span (0.820), and vertical jump (0.903), and the high category for measurement of limb length (0.745). This means that the IAT tool had good validity compared to similar measuring devices. Whereas in the effectiveness device test, the duration of the IAT measurement required an exact time of measurement of 30 minutes 3 seconds, and the SAT measurement required an exact time of measurement of 31 minutes 57 seconds with a measurement time difference of 1 minute 54 seconds. The total duration of IAT measurement required a measurement time of 36 minutes 18 seconds and SAT measurement required a measurement time of 1 hour 7 minutes 27 seconds with a measurement time difference of 31 minutes 9 seconds.

In this study, IAT had the effectiveness of measurement results better than the SAT seen from the exact time of measurement and the total time of measurements made. In line with these results, the use of sensors and the right application can make it easier to monitor activities and measurements [32-34].

\section{Conclusions}

Integrated Anthropometric Test (IAT) can be used to measure anthropometrics and vertical jumps with a very high level of instrument validity for body weight (BW), body height (BH), arm span (AS), vertical jump (VJ), and high category measurements at limb length (LL). Besides, this tool also had a good effectiveness value compared to similar manual measurements seen from a shorter measurement duration. Besides, the superiority of data storage and data processing contained in the measurement application provided easiness for the tester to evaluate the measurement results.

In this study, the measurement of limb length was still in the high validity category. Therefore, for further research, the researchers recommend being able to improve the performance of limb length measuring device so that the device is expected to work more optimally and be able to achieve very high validity so that the accuracy of the device can be improved. Furthermore, the use of the counterbalanced design method was very good to be used in testing the validity of a newly developed device compared to an existing device.

\section{REFERENCES}

[1] W. Huiyao, "China's National Talent Plan: Key Measures and Objectives," Brookings, 2010. [Online]. Available: https://robohub.org/wp-content/uploads/2013/07/Brookings _China_1000_talent_Plan.pdf. [Accessed: 11-Aug-2018].

[2] M. Mansur, Pemanduan Bakat Olahraga. Yogyakarta: Universitas Negeri Yogyakarta, 2011.

[3] J. Brown, Sport Talent; How to Identify and Develop Outstanding Athletes. Canada: Human Kinetik Publisher, 2001.

[4] B. Singh and G. Bhola, "Comparison of Selected Anthropometric Measurements and Physical Fitness of Haryana School Boys in Relation to their Social Status," Indian J. Mov. Educ. Exerc. Sci., vol. 2, no. 2, pp. 1-5, 2012.

[5] D. Z. Sidik, Kajian Identifikasi dan Pengembangan Keberbakatan Olahraga. Bandung: Universitas Pendidikan Indonesia, 2017

[6] J. Y. Wong et al., "Validity and Reliability of Craniofacial Anthropometric Measurement of 3D Digital Photogrammetric ...," Cleft Palate - Craniofacial J., vol. 45, no. 3, pp. 232-239, 2008.

[7] S. Haryono and F. S. Pribadi, "Pengembangan Jump Power Meter Sebagai Alat Pengukur Power Tungkai,” J. Media Ilmu Keolahragaan Indones., vol. 2, no. 1, pp. 15-27, 2012.

[8] T. K. Wie, "Technology and Indonesia's Industrial Competitiveness," 2006.

[9] W. Dhewanto and K. K. Umam, "Technology Commercialisation in Indonesia: Current Condition and Its Challenges," Asian J. Technol. Manag., vol. 2, no. 1, pp. 113, 2009 .

[10] S. J. Haake, "The impact of technology on sporting performance in Olympic sports," J. Sports Sci., vol. 27, no. 13, pp. 1421-1431, 2009.

[11] S. W. Yeargin, P. Kingsley, J. M. Mensch, J. P. Mihalik, and E. V Monsma, "Anthropometrics and maturity status: A preliminary study of youth football head impact 
biomechanics,” Int. J. Psychophysiol., pp. 1-6, 2017.

[12] S. V Caswell et al., "Anthropometrics, Physical Performance, and Injury Characteristics of Youth American Football," Orthop. J. Sport. Med. Group., vol. 4, no. 8, pp. 1-8, 2012.

[13] M. J. Duncan, L. Woodfield, and Y. Al-Nakeeb, "Anthropometric and physiological characteristics of junior elite volleyball players," Br. J. Sports Med., vol. 40, no. 7, pp. 649-651, 2006.

[14] K. Gryko, A. Kopiczko, K. Mikołajec, P. Stasny, and M. Musalek, "Anthropometric Variables and Somatotype of Young and Professional Male Basketball Players," Sports, vol. 6, no. 9, pp. 1-10, 2018.

[15] L.-E. Radu, I.-M. Popovici, and A.-R. Puni, "Comparison of Anthropometric Characteristics between Athletes and Non-athletes," Procedia - Soc. Behav. Sci., vol. 191, pp. 495-499, 2015.

[16] J. R. Fraenkel, N. E. Wallen, and H. H. Hyun, How to Design and Evaluate Research in Education, 8th ed. New York: McGraw-Hill Inc, 2012.

[17] M. Buckthorpe, J. Morris, and J. P. Folland, "Validity of vertical jump measurement devices," J. Sports Sci., vol. 30, no. 1 , pp. 63-69, 2011.

[18] J. C. Stanley, "Statistical Analysis of Scores from Counterbalanced Tests," J. Exp. Educ., vol. 23, no. 3, pp. 187-207, 1955.

[19] ISAK, International Standards for Anthropometric Assessment. Australia: The International Society for The Advancement of Kinanthropometry, 2001.

[20] M. Briggs, Training for Soccer Players. Marlborough: The Crowood Press Ltd, 2013.

[21] R. Ramírez-Vélez, J. E. Correa-Bautista, F. Lobelo, E. L. Cadore, A. M. Alonso-Martinez, and M. Izquierdo, "Vertical jump and leg power normative data for colombian schoolchildren aged 9-17.9 years: The FUPRECOL study," J. strength Cond. Res., vol. 31, no. 4, pp. 990-998, 2017

[22] J. W. L. Keogh, C. L. Weber, and C. T. Dalton, "Evaluation of anthropometric, physiological, and skill-related tests for talent identification in female field hockey," Can. J. Appl. Physiol., vol. 28, no. 3, pp. 397-409, 2003.

[23] D. Ugarkovic and D. M. M. Kukolj, "Standard anthropometric, body composition, and strength variables as predictors of jumping," J. Strength Cond. Res., vol. 16, no. 2 , pp. 227-230, 2002.

[24] E. J. Drinkwater, D. B. Pyne, and M. J. McKenna, "Design and interpretation of anthropometric and fitness testing of basketball players," Sport. Med., vol. 38, no. 7, pp. 565-578, 2008 .

[25] L. Koval, J. Vaňuš, and P. Bilík, "Distance Measuring by Ultrasonic Sensor," IFAC-PapersOnLine, vol. 49, no. 25, pp. 153-158, 2016.

[26] A. Carullo and M. Parvis, "An ultrasonic sensor for distance measurement in automotive applications," IEEE Sens. J., vol. 1, no. 2, p. 143, 2001.

[27] F. Aghili, "Design of a load cell with large overload capacity,” Trans. Can. Soc. Mech. Eng., vol. 34, no. 3-4, pp. 449-461, 2010.

[28] M. Ruffo et al., "New infrared time of-flight measurement sensor for robotic platforms," in IMEKO TC4 International Symposium and International Workshop on ADC Modelling and Testing, 2014, pp. 13-18.

[29] B. Mustapha, A. Zayegh, and R. K. Begg, "Ultrasonic and infrared sensors performance in a wireless obstacle detection system," in 1st International Conference on Artificial Intelligence, Modelling and Simulation, AIMS 2013, 2014, pp. 487-492.

[30] C. Bosco, P. Luhtanen, and P. V. Komi, "A Simple Method for Measurement of Mechanical Power in Jumping," Eur. J. Appl. Physiol., vol. 50, pp. 273-282, 1983.

[31] W. Young, "A simple method for evaluating the strength qualities of the leg extensor muscles and jumping abilities," Strength Cond. Coach, vol. 2, no. 4, pp. 5-8, 1995.

[32] S. Patel, H. Park, P. Bonato, L. Chan, and M. Rodgers, “A Review of Wearable Sensors and Systems with Application in Rehabilitation," J. Neuroeng. Rehabil., vol. 9, no. 21, pp. $1-17,2012$.

[33] L. Nur, P. M. Setiadi, Y. Kusdinar, and A. A. Malik, "Electronic rubric for motivation in physical education," J. Phys. Conf. Ser., vol. 1318, p. 12129, Oct. 2019.

[34] L. Nur, A. Suherman, and H. Subarjah, "The Use of Global Positioning System (GPS) Polars to Determine Motion Intensity,” J. Eng. Sci. Technol., vol. 14, no. 4, pp. 2132 $2139,2019$. 